\title{
EARLY MARKERS OF PROLONGED HOSPITAL STAY IN DEMENTED INPATIENTS: A MULTICENTRE AND PROSPECTIVE STUDY
}

\author{
P.-O. LANG ${ }^{1,2}$, D. ZEKRY'1, J.-P. MICHEL ${ }^{1}$, M. DRAME2,3, J.-L. NOVELLA ${ }^{2,3}$, \\ D. JOLLY ${ }^{2,4}$, F. BLANCHARD 2,3
}

\begin{abstract}
1. Department of rehabilitation and geriatrics, Medical school and University Hospitals of Geneva, Geneva, Switzerland; 2. University of Reims Champagne-Ardenne, School of Medicine, E.A.3797, Reims, France; 3. Department of Gerontology, University Hospitals of Reims, Reims, France; 4. Clinical Research Unit, University Hospitals of Reims, Reims,

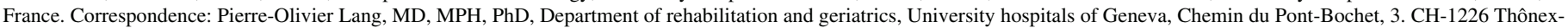
Geneva, Switzerland. Phone: +41 (0)22 30563 20, telex: +41 (0)22 30561 15, E-mail: pierre.o.lang@hcuge.ch
\end{abstract}

\begin{abstract}
Background: Dementia is a serious, chronic, and costly public health problem. Prior studies have described dementia as increasing length of hospital stay, but so far no explanations have been proposed. Methods: To identify early markers for prolonged hospital stay in demented elderly inpatients, 178 communitydwelling or institutionalized subjects aged 75+, hospitalized through an emergency department in 9 teaching hospitals in France, were analyzed. Prolonged hospital stays were defined according a limit adjusted for Diagnosis Related Group. All patients underwent a comprehensive geriatric assessment at admission. Logistic regression multifactorial mixed model was performed. Center effect was considered as a random effect. Results: Of the 178 stays, 52 were prolonged. Most concerned community-dwelling patients (86\%). Multifactor analysis demonstrated that demographic variables had no influence on the length of stay, while diagnosis of delirium (OR 2.31; 95\% CI $1.77-2.91$ ), walking difficulties (OR 1.94; 95\% CI $1.62-2.43$ ) and report by the informal caregiver of moderate or severe burden (OR 1.52; 95\% CI 1.19 - 1.86) or low social quality-of-life score (OR $1.25 ; 95 \%$ CI 1.03 - 1.40), according to the Zarit's Burden Inventory short scale (12 items) and the Duke's Health Profile respectively, were identified as early markers for prolonged hospital stays. Conclusion: At the time of the rising incidence of cognitive disorders, these results suggest that preventive approaches might be possible. In a hospital setting as well as in a community-dwelling population, more specific, specialized and coordinated care, using the expertise of multiple disciplines appears as a probable effective measure to limit prolonged hospital stay. Such approaches require (i) clear patient-oriented goal definition, (ii) understanding and appreciation of roles among various health care and social disciplines and, (iii) cooperation between partners in patient's management. However, the cost- and health-effectiveness of such approaches should be evaluated.
\end{abstract}

Key words: Prolonged hospital stay, dementia, elderly, SAFEs cohort.

\section{Introduction}

Dementia is a serious, chronic, and costly public health problem (1), afflicting at least 5 million people in Europe. It is one of the most disabling health conditions in older adults (2). Dementia is associated with significant physical, social and psychiatric disabilities, and imposes a significant burden and distress on informal and professional caregivers (3).

Weiner et al. reported that $63 \%$ of the Medicare costs for patients with dementia consist of payments for inpatient hospital care.4 Higher costs are likely to be driven directly by longer lengths of stay. Nevertheless, if several studies have described dementia as a predictive or explanatory factor for overall length of stay (5-7), the reasons for the lengthening of hospitalisations are still uncertain and mainly the subject of speculation.

Once admitted to hospital, older adults and especially demented patients are exposed to increased functional, physical and/or mental impairments which increase the length of stay (5). Thus, detrimental effects on the level of dependence, on continence, and on nutritional status, as well as adverse drug effects and the occurrence of cross infection, have been described as explanatory factors (8). Other proposed causal factors are longer recovery time and/or later discharge related to securing appropriate institutional placement (9-11).

Beyond financial considerations, to counter the increasing risk of functional, physical and/or mental decline, targeted care policies to prevent prolonged hospitalization in demented inpatients seem necessary. The early identification of patients at risk for prolonged hospital stay immediately at admission appears to be a necessary step. With this aim the present study analyses a group of demented patients at the time of their hospital admission through emergency circumstances.

\section{Materials and Methods}

\section{Study population}

The population of the study was drawn from the 'Sujet Âgé Fragile - Evaluation et suivi' (SAFEs) cohort. The study design, cohort sampling procedures, and inclusion and noninclusion criteria have already been published (5). Briefly, 1306 subjects aged 75 or over were hospitalized through Emergency Departments (ED) in nine teaching hospitals. Among them, 178 patients $(13.6 \%)$ with a confirmed diagnosis for dementia prior to admission and irrespective of aetiology were considered (figure 1). For ethical aspects, informed consent was signed by each willing subject and/or their families or legal representative. This study was performed in accordance with 
the Declaration of Helsinki and current French law relating to biomedical research involving human subjects.

\section{Figure 1}

Flow chart for the study cohort selection proceedings

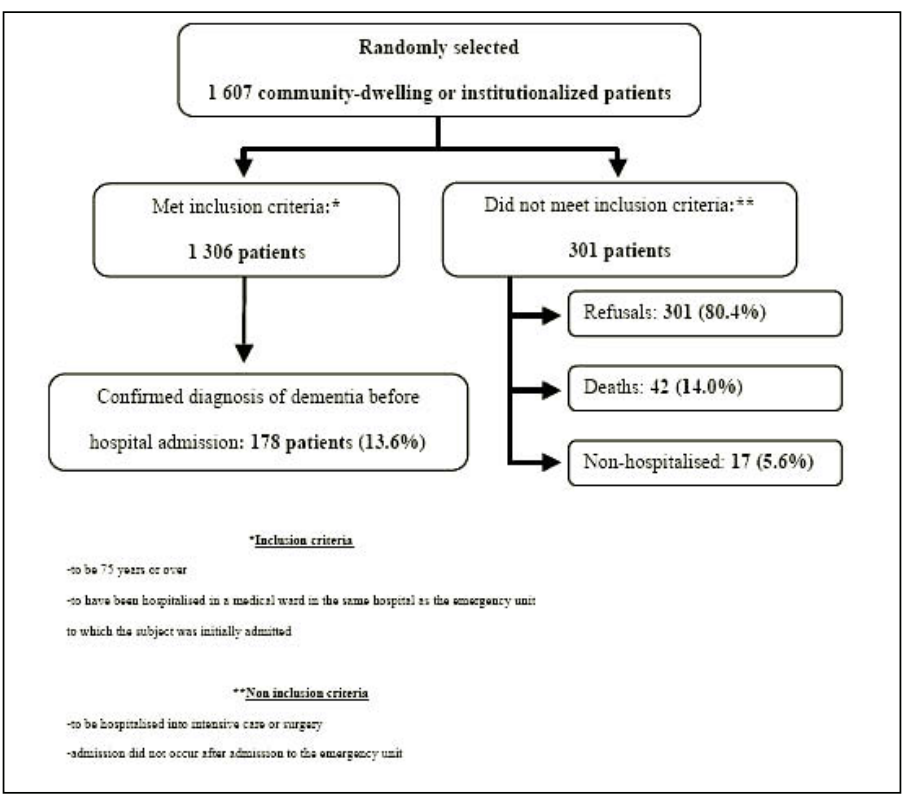

Each patient included was interviewed and evaluated by a geriatrician, assisted by a member of the health-care team, the principle caregiver, or both. This comprehensive geriatric assessment (CGA), presented below, gathered a large quantity of clinical and sociodemographic data concerning caregivers and patients.

Informal caregiver burden and quality of life (QoL) were assessed, respectively using Zarit's Burden Inventory short scale and Duke Health Profile (12-14). The brief version of the Zarit Caregiver Burden inventory is composed of 12 items exploring how caregivers feel when they are taking care of another person. Caregivers rated each item on a 5-point scale from 0 (never) to 4 (nearly always), yielding a possible range of 0 to 44 . Higher values indicated greater levels of caregiver burden. A moderate or severe caregiver's burden was defined as a score $>17$. The Duke Health Profile is a 17-item generic self-report instrument containing six health measures (physical, mental, social, general, perceived health, and self-esteem), and four dysfunction measures (anxiety, depression, pain, and disability). The ten dimensions exploring the caregiver's QoL are presented in the form of a normalized scale: 0 (worst QoL) to 100 (best possible QoL).

\section{Comprehensive Geriatric Assessment}

The patient's CGA conducted at hospital admission consisted in the assessment of:

Patient's demographic characteristics and social environment. Information about living situation (private home or institution), marital status (single, married, divorced or widowed), and different types of assistance at home (informal and professional caregivers; technical assistance) were recorded. Professional assistance refers to professional caregivers such as nurse, physiotherapist, meals on wheels, home helps, cleaners, speech therapist and/or psychologist (15).

Patient's functional abilities: functional abilities at baseline and at inclusion were assessed using Katz's Activities of Daily Living (ADL) scale (16). Baseline ADLs were defined as the dependence level of the subject before occurrence of the event motivating hospitalization (performance in ADLs 2 weeks before admission). Dependency for the ADL was defined according to the ability/inability of the subject to perform the following activities: bodily care, dressing, using the toilet, moving about and feeding (table 1). Only 5 of the 6 ADL in the Katz scale were taken into consideration (continence was not included in accordance with the recommendations in the literature) (17), and were used to construct a three-level, fiveitem ADL scale. Not disabled was defined as independent for all items, moderately disabled as dependent for one or two items, and severely disabled as dependent for three or more items. These scores defined three main groups, which ranged from a group capable of performing basic activities independently to a group that was dependent in the majority of the five basic activities. Baseline ADLs were used to construct a five-level, five-item ability scale to detect changes in ADLs. Five change levels were defined according to the number of ADLs for which the patient was independent. Not disabled described subjects who were independent for baseline ADLs and inclusion ADLs, appearance of disability described subjects who were independent for baseline ADLs but who were dependent for one or more items in inclusion ADLs, increased disability described subjects who were dependent for one or more items for baseline ADLs and who added two or more items for inclusion ADL, disability improvement described subjects who were dependent for one or more items for baseline ADLs and who lost two or more items for inclusion ADL, and stability in disability described subjects who were dependent for one or more items for inclusion ADLs and had one or more item for baseline ADLs. These scores defined five main groups corresponding to five change profiles in ADL abilities between baseline and inclusion (5).

Walking and balance difficulties were respectively estimated by the Timed Get Up and Go Test and the One-Leg-Balance Test: More than 20 seconds to complete the Timed Get-up and Go Test was considered to have walking difficulties; inability to stand on either leg at least 5 seconds was considered to have balancing difficulties $(18,19)$.

Patient's psychiatric condition: a mood disorder was defined according to Schwab et al. and Gilleard et al., as a score of 14 and over $(20,21)$. Delirium was clinically diagnosed at the bedside by a geriatrician according to the 4 essential features in DSM IV: inattention, change in cognition, acute and fluctuating mood states and evident medical cause (22).

Patient's nutritional status: a risk of malnutrition was defined by a Mini Nutritional Assessment Short Form score $<12$ (MNA-sf score ranges 14-0) (23). Risk for the patient for 


\section{JNHA: CLINICAL NEUROSCIENCES}

developing pressure ulcers: using the Norton scale (score ranges: 20-5), a risk of pressure sores was defined by a score $<15$ (24).

\section{Table 1}

Inclusion characteristics of SAFEs cohort patients with dementia $(\mathrm{N}=178)$

\begin{tabular}{|c|c|c|c|}
\hline \multirow{2}{*}{\multicolumn{2}{|c|}{$\begin{array}{l}\text { Activities of Daily Living } \\
\text { Characteristics }\end{array}$}} & \multicolumn{2}{|c|}{ Hospital stays } \\
\hline & & $\begin{array}{c}\leq \text { f-DRG limit } \\
\text { n }(\%)\end{array}$ & $\begin{array}{c}>\text { f-DRG limit } \\
\text { n }(\%)\end{array}$ \\
\hline \multirow[t]{4}{*}{ Katz's ADL (D-15)*† } & Not disabled & $39(30.9)$ & $15(28.8)$ \\
\hline & Moderately disabled & $24(19.0)$ & $11(21.1)$ \\
\hline & Severely disabled & $63(50.0)$ & $26(50.0)$ \\
\hline & & \multicolumn{2}{|c|}{$\mathrm{p}=0.8$} \\
\hline \multirow[t]{4}{*}{ Katz's ADL (D0)* } & Not disabled & $13(10.3)$ & $7(13.5)$ \\
\hline & Moderately disabled & $28(22.2)$ & $18(34.6)$ \\
\hline & Severely disabled & $85(67.5)$ & $27(51.9)$ \\
\hline & & \multicolumn{2}{|c|}{$\mathrm{p}=0.4$} \\
\hline \multirow[t]{6}{*}{ Change in $\mathrm{ADL} *$} & Not disabled & $8(6.3)$ & $3(5.8)$ \\
\hline & Appearance of disability & $20(15.9)$ & $14(26.9)$ \\
\hline & Increased disability & $25(19.8)$ & $10(19.2)$ \\
\hline & Disability improvement & $7(5.6)$ & $2(3.8)$ \\
\hline & Stability in disability & $66(52.4)$ & $23(44.3)$ \\
\hline & & \multicolumn{2}{|c|}{$\mathrm{p}=0.6$} \\
\hline
\end{tabular}

* Katz's Activities of daily living (ADL): Not disabled = independent for all ADL; Moderately disabled $=$ dependent for 1 or 2 ADL; Severely disabled $=$ dependent for 3 or more ADL. $\dagger$ D-15: ADL before admission (assessed retrospectively at inclusion). \$ Change in ADLs $=(\mathrm{D} 0)-(\mathrm{D}-15):$ Not disabled $=$ independent for D-15 and D0 ADLs; Appearance of disability $=$ independent for D-15 and dependent for 1 or more ADL at D0; Increased disability $=$ dependent for 1 or more ADL at D-15 and increased dependence for 2 or more $\mathrm{ADL}$ at D0; Disability improvement $=$ dependent for 1 or more ADL at D-15 and decreased dependence in 2 or more $\mathrm{ADL}$ at D0; Stability in disability $=$ dependent for 1 or more ADL at both D-15 and D0.

The level of severity of patient's comorbidities: a modified version of the Charlson index (CI applicable to pathologies coded in ICD-10) made it possible to establish three levels of severity for co-morbidity: mild co-morbidity $(\mathrm{CI}<2)$, moderate co-morbidity $(2 \leq \mathrm{CI} \leq 4)$ and severe co-morbidity $(\mathrm{CI} \geq 5)$. These thresholds have already been used by other authors (25).

\section{Geriatric syndromes}

Based on the CGA, a clinical profile for each patient was developed according to the clinical opinion of the geriatrician. This profile is presented in the form of 8 geriatric syndromes: delirium, mood disorders walking difficulties, gait and balance disorders, malnutrition risk, bedridden, pressure sore risk, and incontinence (table 2).

\section{Prolonged hospital stay definition}

The length of stay was defined as the interval between the admission and the discharge dates from a single hospital. The case-mix-based prospective hospital payment system (in French T2A: Tarification à l'activite - charge related to activity) is the framework for the funding of European health-care facilities. The French Diagnosis-Related Group (f-DRG) is a classification into 698 DRGs which defines homogeneous groups of patients who have equivalent medical resource consumption during their stay. In the T2A, each DRG yields: a national mean length of stay, the reference value for health insurance payment for the stay within limits corresponding to the minimum and maximum lengths for the DRG considered. The upper limit was chosen to define prolonged stays (5).

Table 2

Inclusion characteristics of SAFEs cohort patients with dementia $(\mathrm{N}=178)$

\begin{tabular}{|c|c|c|c|}
\hline \multirow{2}{*}{ Characteristics } & & \multicolumn{2}{|c|}{ Hospital stays } \\
\hline & & $\begin{array}{c}\leq \text { f-DRG limit } \\
\text { n }(\%)\end{array}$ & $\begin{array}{c}>\text { f-DRG limit } \\
\text { n }(\%)\end{array}$ \\
\hline \multicolumn{4}{|c|}{ Sociodemographic informations } \\
\hline Gender & $\begin{array}{l}\text { Men } \\
\text { Women }\end{array}$ & $\begin{array}{l}39(30.9) \\
87(69.1)\end{array}$ & $\begin{array}{l}20(38.5) \\
32(61.5)\end{array}$ \\
\hline Age (year) & Mean \pm SD & $87.5 \pm 5.7$ & $85.7 \pm 5.9$ \\
\hline Living situation & $\begin{array}{l}\text { Private home } \\
\text { Institution }\end{array}$ & $\begin{array}{l}99(78.6) \\
27(21.4)\end{array}$ & $\begin{array}{c}45(86.5) \\
7(13.5)\end{array}$ \\
\hline Marital status & $\begin{array}{l}\text { Single } \\
\text { Married } \\
\text { Divorced } \\
\text { Widowed }\end{array}$ & $\begin{array}{c}7(5.5) \\
38(30.2) \\
8(6.4) \\
73(57.9)\end{array}$ & $\begin{aligned} 2 & (3.9) \\
16 & (30.8) \\
5 & (9.6) \\
29 & (55.7)\end{aligned}$ \\
\hline Professional caregiver & Yes & \multicolumn{2}{|c|}{$\mathrm{p}=0.6$} \\
\hline Informal caregiver & Yes & \multicolumn{2}{|c|}{$p=0.7$} \\
\hline $\begin{array}{l}\text { Moderate to Severe infor } \\
\text { caregiver's burden } \\
\text { Medical informations }\end{array}$ & & \multicolumn{2}{|c|}{$\mathrm{p}<0.01$} \\
\hline Delirium & Yes & \multicolumn{2}{|c|}{$\mathrm{p}<0.001$} \\
\hline Mood disorders & Yes & \multicolumn{2}{|c|}{$\mathrm{p}=0.5$} \\
\hline Walking difficulties & Yes & \multicolumn{2}{|c|}{$\mathrm{p}<0.01$} \\
\hline Gait and balance disorder & s Yes & \multicolumn{2}{|c|}{$p=0.7$} \\
\hline Malnutrition risk & Yes & $p=0.4$ & $46(88.5)$ \\
\hline Bedridden & Yes & $\mathrm{p}=0.5$ & $9(17.3)$ \\
\hline Pressure sores risk & Yes & \multicolumn{2}{|c|}{$\mathrm{p}=1.0$} \\
\hline Incontinence & Yes & \multicolumn{2}{|c|}{$\mathrm{p}=0.7$} \\
\hline Comorbidity index level & $\begin{array}{l}\text { Mild } \\
\text { Moderate } \\
\text { Severe }\end{array}$ & $\begin{array}{c}86(68.1) \\
37(29.8) \\
3(2.4)\end{array}$ & $\begin{array}{c}36(69.2) \\
15(28.8) \\
1(1.9)\end{array}$ \\
\hline & & \multicolumn{2}{|c|}{$p=0.9$} \\
\hline
\end{tabular}

\section{Statistical analysis}

A descriptive analysis using socio-demographic characteristics, functional and nutritional status, level of comorbidity, and psychiatric symptoms (delirium, mood disorder) of demented patients, and informal caregivers' burden and quality of life as independent variables was performed. Descriptive results pertaining to numerical variables are presented in the form of mean, standard deviation (SD). For length of stay both mean \pm SD and median are presented. For categorical variables, sample sizes and percentages calculated are presented. Patient characteristics were compared with respect to their length of stay (prolonged or not). The tests used were chosen according to the type of variable and the sample size (categorical variables: $\chi 2$ or Fisher's exact tests; numerical 


\section{EARLY MARKERS OF PROLONGED HOSPITAL STAY IN DEMENTED INPATIENTS}

variables: Student's t-test).

The single factor analysis results identified the variables associated with prolonged stays as previously defined. The selection threshold for the useful variables in multifactor analysis was set at $\mathrm{p}=0.20$ (tables 1 to 3 ).

\section{Table 3}

Multiple logistic regression analysis of predictive factors for a prolonged hospital stay, defined by a f-DRG-adjusted limit, in older demented patients. Results are given as odds ratio (OR) and its $95 \%$ confidential interval $(95 \% \mathrm{CI}-\mathrm{N}=178)$

\begin{tabular}{|c|c|c|c|c|}
\hline \multirow[t]{2}{*}{ Characteristics } & & \multicolumn{3}{|c|}{$\begin{array}{l}\text { Early markers of prolonged hospital stay } \\
\text { Stay }>\text { f-DRG-adjusted limit }\end{array}$} \\
\hline & & OR & $95 \% \mathrm{CI}$ & $\mathbf{p}$ \\
\hline \multirow[t]{2}{*}{ Delirium } & No & 1 & I & $<0.01$ \\
\hline & Yes & 2.31 & $1.77-2.91$ & \\
\hline \multirow[t]{2}{*}{ Walking difficulties } & No & 1 & I & 0.09 \\
\hline & Yes & 1.94 & $1.62-2.43$ & \\
\hline \multirow[t]{2}{*}{ Severe caregiver's burden } & No & 1 & l & $<0.01$ \\
\hline & Yes & 1.52 & $1.19-1.86$ & \\
\hline $\begin{array}{l}\text { Duke's health profile } \\
\text { Social QoL score }\end{array}$ & Caregiver & 0.80 & $0.71-0.97$ & $<0.01$ \\
\hline
\end{tabular}

All the variables thus selected were introduced into a logistic regression multifactorial model. It considers the effect of each factor after adjustment for all the other factors. The variables generated by the geriatric evaluation were considered to be fixed-effect variables, the inclusion center (i.e. hospital) as a random-effect factor, in a multifactor mixed model. The variables "age", "gender" and "inclusion centre" were forced into the model. The effects of the other variables were systematically adjusted for them. Multifactorial analyses were computed with the GLIMMIX macro SAS® software, using a backward elimination procedure (exit threshold $\mathrm{p}=0.10$ ) with authorized re-entry. Interaction variables, associating the inclusion center and the different descriptive variables were also tested. The results of these analyses were presented as odds ratios (OR) and their 95\% CI. Even if, in this type of multifactorial model, the random factor "center"' is controlled, this variable does not appear in the table of results (Table 3). In a mixed model, the random factor is considered to be a distribution. The global center effect is given as a mean effect and its standard deviation. Each center considered is presented as a deviation from the mean effect (26).

To analyze possible multicollinearity between variables, Spearman correlation coefficients (r) were calculated.

\section{Results}

The 178 stays analyzed amounted to 3.738 hospitalization days. Seventy three patients were hospitalized in an Acute Care for the Elderly unit (41\%) and 18 of all stays were multi-unit $(10 \%)$. This type of stay tended to foster prolongation regardless of the T2A limit considered. However this factor was not considered in the multi-factor analysis model. This variable, which was only known at the end of the stay, could not be considered in the predictive approach. Likewise for the occurrence of patient death $(7 \%)$ which is also associated with stay prolongation. Higher death rate was observed amongst patients with prolonged hospital stays (15\% vs $4 \%$ ). The mean length of stay was 21 days (SD \pm 19$)$. Half of the discharges took place before the 14th day (median length of stay). Fifty two stays were longer than the f-DRG adjusted limit (29\%); $86 \%$ concerned community-dwelling patients.

Patients' socio-demographic characteristics, descriptive data on dependency level, on co-morbidity level and the 8 geriatric syndromes classification are presented in tables 1 and 2 . Caregivers' evaluation data are presented in table 2. Two thirds of the cohort were women $(69 \%)$. The average age \pm SD was $86 \pm 6$ years (range 75-103). Eighty-six percent of subjects living at home $(n=144)$ and $50 \%$ in institution $(n=34)$ reported having an informal caregiver.

Amongst them, in the informal caregiver interviews, nearly $66 \%$ reported feeling a "moderate or severe" care burden according to the Zarit's Burden Inventory. In the social dimension, the QoL score, according to Duke's health profile, was significantly lower when the stay was prolonged.

In un-adjusted analysis, no demographic and social characteristics, and descriptive variable for the level of dependence (baseline and inclusion ADLs or changes in ADL) had statistical influence on prolongation of stay. A clinical diagnosis of delirium and walking difficulties were significantly associated with the prolongation of the hospital stay $(\mathrm{p}<0.05)$.

Multicollinearity analysis showed that all Spearman $r$ calculated between variables with unifactorial $\mathrm{p} \leq 0.3$ were weak.

The ORs, calculated using exact logistic regression model, are presented in table 3. Following single factor analysis results, candidate variables for multivariate analysis, in addition to those forced in the model ("age", "gender" and "centre"), were "moderate or severe informal caregiver's burden", "delirium", and "walking difficulties". All interaction variable p-values were higher than the exit threshold. The multifactorial analysis results demonstrate that demographic data have no predictive value for prolongation of stay. Adjustment for the fDRG reveals two clinical markers: a clinical diagnosis of delirium within the first week of hospitalization (OR 2.31; 95\% CI 1.77-2.91) and walking difficulties (OR 1.94; 95\% CI 1.62-2.43) were identified as early markers of prolonged hospital stay in demented patients. In addition, social environment data seems to have a predictive value. The report by informal caregivers of a "moderate or severe burden" (OR $1.52 ; 95 \%$ CI 1.19-1.86) or a low score in the social life dimension (OR 1.25; 95\% CI 1.03-1.41 - calculated for a 10point decrease in the global score) was likewise associated with prolonged stays exceeding the f-DRG adjusted limit. 


\section{JNHA: CLINICAL NEUROSCIENCES}

\section{Discussion}

This prospective study, concerning 178 demented patients hospitalized in emergency, has shown that nearly $30 \%$ of subjects had lengths of stay exceeding the f-DRG adjusted limit. A clinical diagnosis of "delirium" and "walking difficulties" as well as a "moderate or severe informal caregiver burden" and/or a "low social QoL score" according to Duke's health Profile, were found to be early markers of prolonged hospital stays in the targeted population.

Prolonged stays are defined here using a f-DRG-adjusted limit. The limit is adjusted for the condition that required the most resources during the stay. The markers are thus identified after adjustment for the main medical problem treated during the stay. Even if this classification does not adequately describe the resources consumed by older inpatients, it has been used in France since 2004 to identify outlier stays within the framework of the case-mix-based prospective hospital payment system. This classification takes into account neither the social nor the functional dimensions of the geriatric treatment of older patients (5).

The definition of a prolonged stay using this f-DRG-adjusted limit enables the identification of two clinical factors as early markers of prolongation of stay: delirium and walking difficulties. Delirium is frequently encountered in acute medical care settings in older adults (27). The physiology of ageing, with an age-related decline in cerebral blood flow and lower concentrations of brain neurotransmitters, partially explains why older adults are more likely to develop delirium. These changes result in less physiological reserves to cope with the additional stress linked to metabolic disturbances and acute diseases, and in particular with the stress related to dementia (28). Numerous clinically relevant outcomes associated with delirium have been described: inability to participate in rehabilitation, functional decline during hospital stay, and a 5fold increase in nursing home placements. These factors probably contribute to lengthening hospital stays. Delirium and dementia are highly interrelated. Dementia is one of the leading risk factors for delirium $(27,29)$. The exact nature of their interrelationship remains poorly documented, and a causeeffect relationship has not been established. The underlying vulnerability of the brain in demented patients may predispose to delirium (27). However, prevention of delirium and related adverse events can avoid prolonged hospital stay in demented older patients. As delirium has many causes, multi-component preventive approaches are often necessary. As demonstrated in the literature, by targeting high-risk patients at admission and/or by earlier therapeutic management, it is possible to anticipate the occurrence of delirium $(27,29,30)$. Thus, early screening for delirium by identifying related risk factors could be the first step in the prevention of prolonged hospital stay.

Once delirium is present, the key steps in management are to address all evident causes, provide supporting care, prevent complications and treat behavioural symptoms (27). In the present study, delirium was clinically assessed solely according to the geriatrician's experience. However, instrument and diagnostic algorithms for identification of delirium are available today. The four main instruments are the Confusion Assessment Method (CAM), the Delirium Rating Scale, the Delirium Symptom Interview, and the Memorial Delirium Assessment Scale $(30,31)$. Their utilization in this work would have allowed clinicians to more accurately diagnose, and would have given valuable comparison opportunities with other studies.

Other authors have found walking difficulties as a marker of prolonged hospital stays (5). Prolonged confinement to bed due to an acute pathology often aggravates walking difficulties and increases the risk of fall. Neurological, neuromuscular, osteoarticular, and visual factors are associated with walking disorders, as are motor and mental inhibitions arising from mood disorders. In addition, the use of psychotropic medication for treatment of BPSD contributes to this geriatric syndrome. Because of its effects on muscle strength and on the peripheral and central neurological structures, protein-caloric malnutrition is also an associated factor (5). While impairment in cognitive functioning impacts the patient's mobility, older people with lower levels of cognition do nevertheless improve their functional abilities as a result of participation in exercise rehabilitation programs. Two meta-analyses focusing on the effects of exercise training on older adults with dementia have demonstrated that exercise training increases fitness, physical function, cognitive function, and positive behaviour in people with dementia and cognitively impaired patients have similar strength and endurance training results to cognitively intact older participants after adjustment for age and gender (32). In addition to early rehabilitation and mobilization, early attention to nutrition and, if needed, prescription of nutritional supplements, might be of great benefit among the older hospitalized patients. Protein-calorie malnutrition, frequent in old people, leads to muscular loss the functional consequences of which are particularly damaging (33). During any hospital stay, fasting in connexion with the performance of certain examinations, the sometimes inadequate help with feeding and/or the anorexic effect of certain types of medication will lead to a reduction in protein and calorie intakes. To compensate, the body will draw on muscle energy reserves, already low at the time of admission, and precipitate the loss of muscular strength (34).

The report by informal caregivers of the presence of a moderate or severe burden or a poor social quality of life were also identified as independent markers for prolonged stays. Numerous studies have suggested that primary caregiver factors are related to the hospitalisation of the care recipients in particular unplanned hospital admission of older patients in emergency circumstances (35). The exhaustion of informal caregivers has been found to be an independent predictive factor for hospitalization and admission to an institution in demented older adults $(36,37)$. Behavioural and psychological 


\section{EARLY MARKERS OF PROLONGED HOSPITAL STAY IN DEMENTED INPATIENTS}

symptoms related to dementia (BPSD) are well-recognised factors associated with distress and burden in caregivers. They also affect the caregiver's QoL (37). One of the main limitations of this study is probably the lack of BPSD assessment within the CGA, while several assessment tools could have been used. The most useful is the Neuro-psychiatric Inventory (38). BPSD is not the only explicative factor in family/informal caregiver burden; other factors contribute to informal caregivers' exhaustion. Imbert et al. have shown, in demented community-dwelling older adults, the considerable involvement of family members and persons close toward their old people (39). This observation has been made in numerous other industrial countries, where informal caregivers are considered as a central mainstay of the "living at home" health policies.40 As professional support is mostly restricted to technical interventions, family and informal support takes the form of routine assistance in almost every aspect of everyday life including personal hygiene. Indeed, professional nursing care predominantly concerns the most dependent old people. As a reflection of the daily self-sacrifice of family and persons close, a low score in the social dimension of the Duke's health profile was also identified as marker for prolonged hospital stays. Keeping older subjects with dementia in their homes has many social consequences for family and informal caregivers. Many concessions are required, whether in terms of hours devoted to the elderly person, lost leisure hours, or coping with their own professional and family responsibilities (39). Thus a better understanding and management of informal caregiver burden and their reluctance towards accepting professional caregivers, is needed, as well as the development of alternative solutions to hospital to resolve crisis situations. The development of a health care network and day centres for older adults with dementia might limit hospital stay extension arising from family reluctance towards patient discharge. However, improvement of the cares coordination using the expertise of multiple disciplines might be another but more adequate answer to the increasing complexity of care in hospitalized older adults and moreover with dementia. Nowadays, it is widely recognized that interdisciplinary team care is essential for effective management of complex patients such as the frail elderly (41). In demented patient, the study results suggest the necessity of more specific and specialized cares. The integration of clinical nurse specialists in mental health in the usual care team will be an overhang in hospital care setting. Under the leadership of these nurse specialists the care team might develop comprehensive cares and discharge plans for patients with dementia, implemented across a care continuum (42). Systematic screening for delirium might be devoted to these nurse specialists according validated screening tools, as CAM for example, at admission time and all along the stay. Focusing on knowledge development, effective collaboration between nurses and nurse specialists might lead to practical solutions to clinical problems for example in the non pharmacological management of BPSD. In addition, an active and daily collaboration between geriatrician and geriatricpsychiatrician might be useful in the psychotropic management of BPSD. Strategies for pharmaceutical approaches, in old, frail, co-morbid and often poly-medicated patients have to be carefully considered (43). To limit delirium during the stay a particular attention should be done in therapeutic management, other than psychotropic, to limit drug-drug and/or drug-disease interaction in this vulnerable population. During hospitalization, informal caregivers should, as early as possible, be provided with psychological supports to enable them to express their feelings and fears for the future. As soon as possible at the beginning of the hospital stay, and regularly thereafter, social workers could contact informal caregivers to assess living conditions in the home, plan the discharge, and up-date the care provision plan in accordance with the development of the acute disease(s). Such as management, in a specialized unit known under the acronym SOMADEM (somatic and dementia) has been develop in the Geneva academic department of geriatrics. Acceptability, effectiveness and cost-effectiveness of such care programme will be soon assessed.

Similarly, interdisciplinary team care should be developed in community elderly with dementia (44). Such as team, might help general practitioner in their management of demented patient at home, with technical and practical supports. One key stone of the successful of such as care management is the improvement of networks between acute care nurses and physicians and, in-home care team. Robinson et al have demonstrated that ward nurses have, at best, a limited knowledge and understanding of the aged care system, its function, or how to access services. They need assistance to develop their knowledge of services available to support older people following discharge (45). Practical strategies such as case study approach, and/or interactive forums might support collaboration between ward nurses and community providers and/or multi disciplinary assessment services. Providing an effective ward/community networks will facilitate discharge planning of older people with dementia and why not might limit social hospitalizations.

\section{Conclusion}

This study demonstrates that a set of simple items enables a predictive approach to the length of stay of older demented patients, hospitalized in emergency circumstances. Delirium, walking difficulties and subjective increase of family/informal caregiver burden were identified as being early markers. At the time of the rising incidence of cognitive disorders in developed countries, these results suggest that preventive approaches might be possible. As well as in hospital setting and in community-dwelling population, coordination of cares using the expertise of multiple disciplines appear as probable effective measures to limit prolonged hospital stay. Such as approaches require communications; clear patient-oriented goal 


\section{JNHA: CLINICAL NEUROSCIENCES}

definition; an understanding and appreciation of role among various disciplines. However, the cost- and health-effectiveness of such approaches should be evaluated in controlled studies.

Acknowledgments: (1) We are grateful to the Ministère de la Santé (France), the Caisse Nationale d'Assurance Maladie des Travailleurs Salariés and the Institut de la Longévité et du Vieillissement (INSERM, France) for their financial support. (2) To all other members of the SAFEs cohort group for their participation in the cohort design: Clinical Gerontology Centre, Montpellier Teaching Hospital (Claude Jeandel); Geriatrics Geriatric Department, Public Assistance-Hospitals of Paris, European Hospital Georges Pompidou (Olivier Saint-Jean); Public Assistance-Hospitals of Paris, Sainte Perrine Hospital (Joel Ankri); Department of Clinical Gerontology, University Hospitals of Saint Etienne (Regis Gonthier); Department of Internal Medicine and geriatrics, University Hospitals of Strasbourg (Damien Heitz); Department of Internal Medicine and Geriatrics, University Hospitals of Nimes (Benoît De Wazières).

Conflicts of interest: "none declared" for this manuscript. The financial sponsors played no role in the design, execution, analysis and interpretation of data, or writing of the manuscript.

Financial disclosure: None of the authors had any financial interest or support for this paper.

\section{References}

1. Fillenbaum G, Heyman A, Peterson BL, Pieper CF, Weiman AL. Use and cost of hospitalization of patients with AD by stage and living arrangement. Neurology 2001;56:201-6.

2. Üstüm TB, Rehm J, Chatterji S, Saxena S, Trotter R, Room R, Bickenbach J et al. Multiple-informant ranking of the disabling effects of different health conditions in 14 countries. Lancet 1999;354:111-5.

3. Waldemar G, Dubois B, Emre M, Georges J, McKeith IG, Rossor M, Scheltens P, Tariska P, Winblad B. Recommendations for the diagnosis and management of Alzheimer's disease and other disorders associated with dementia: EFNS guideline. Eur J Epidemiol 2006;14:e1-e26.

4. Weiner M, Powe N, Weller WE, Shaffer TJ, Anderson GF. Alzheimer's disease under managed care: implications from Medicare utilization and expenditure patterns. J Am Geriatr Soc 1998;46:762-70.

5. Lang PO, Heitz Damien, Hedelin G et al. Early markers of prolonged hospital stays in older people: a prospective, multicenter study of 908 inpatients in French acute hospitals. J Am Geriatr Soc 2006;54:1031-9.

6. Lyketsos CG, Sheppard JM, Rabins PV. Dementia in elderly persons in general hospital. Am J Psychiatry 2000;157:704-7.

7. Satish $\mathrm{S}$, Winograd $\mathrm{CH}$, Cavez $\mathrm{C}$, Bloch $\mathrm{D}$ Geriatric targeting criteria as predictor of survival and health care utilization. J Am Geriatr Soc 1996;44:914-21.

8. Eaker ED, Mickel SF, Chyou PH, Mueller-Rizner NJ, Slusser JP. Alzheimer's disease or other dementia and medical care utilization. Ann Epidemiol 2002;12:39-45.

9. Lang PO, Ebel M, Hasenfratz A, Autelitano-Boohs AM, Bandelier S, Boudebouda Y et al. Disabled elderly people waiting for institutionalization from a hospital ward: prospective study in the administrative district of Strasbourg (France). Rev Epidemiol Sante Publique 2008;56:87-95.

10. Margiotta A, Bianchetti A, Ranieri P, Trabucchi M. Clinical characteristics and risk factors of delirium in demented and not demented elderly medical inpatients. J Nutr Health Aging 2006;10:535-9.

11. van Zyl T, Seitz DP. Delirium concisely: condition is associated with increased morbidity, mortality, and length of hospitalization. Geriatrics 2006;61:18-21.

12. Zarit SH, Reever KE, Bach-Peterson J. Relatives of impaired elderly: Correlates of feelings of burden. Gerontologist 1980;20:649-55

13. Pakerson GR, Broahead WE, Tse CKJ. The Duke Health Profile. A 17-item measure of health and dysfunction. Med Care 1990;28:1056-72.

14. Bedard M, Molloy DW, Squire L, Dubois S, Lever JA, O'Donnell M. The Zarit Burden Interview: a new short version and screening version. Gerontologist 2001;41:652-7.

15. Weinberg DB, Lusenhop RW, Gittell JH, Kautz CM Coordination between formal providers and informal caregivers. Health Care Manage Rev 2007;32:140-9.

16. Katz S. Assessing self-maintenance. Activities of daily-living, mobility and instrumental activities of daily-living. J Am Geriatr Soc 1983;31:721-7.

17. Fillenbaum GC. Functional ability. In: Ebrahim S, Kalache A, eds Epidemiology in Old Age. London: BMJ Publishing Group; 1996:228-35.

18. Vellas B, Wayne SJ, Baumgartner RN et al. One-leg-balance is an important predictor of injurious falls in older persons. J Am Geriatr Soc 1997;45:735-8.

19. Podsialdo D, Richardson S. The timed "Get up \& Go": A test for basic functional mobility for frail elderly persons. J Am Geriatr Soc 1991;39:142-8.

20. Schwab JJ, Holzer CE, Warheit GJ. Depressive symptomatology and age. Psychosomatics 1973;14:135-41.

21. Gilleard CJ, Willmott M, Viddadi KS. Self-report measures of mood and morale in elderly depressive. Br J Psychiat 1981;138:230-5.

22. American Psychiatric Association. Diagnosis and Statistical Manual of mental Disorders, 4th Ed. Washington, DC: American Psychiatric Association; 1994

23. Rubenstein LZ, Harker JO, Salva et al. Screening for undernutrition in geriatric practice: Developing the short form mini-nutritional assessment (MNA-sf). J Gerontol A Biol Sci Med 2001;56:M366-M72.

24. Norton D, Mclaren R, Exton-Smith AN. An investigation of nursing problems in hospitals. New York: Churchill Livingstone; 1975.

25. Sundararajan V, Henderson T, Perry C, et al. . New ICD-10 version of the Charlson Comorbidity Index predicted in-hospital mortality. J Clin Epidemiol 2004;57:1288-94.

26. Brown H, Prescott R. Applied mixed model in medicine. New-York: John Willey \& Sons; 2000.

27. Inouye SK. Delirium in older persons. N Engl J Med 2006;354:1157-65.

28. Flacker JM, Lipsitz LA. Neural mechanisms of delirium: current hypotheses and evolving concepts J Gerontol A Biol Sci Med Sci 1999;54A:B239-46.

29. Cole MG. Delirium in elderly patients. Am J Geriatr Psychiatry 2004;12:7-21.

30. Casarett DJ, Inouye SK Diagnosis and management of delirium near the end of life. Ann Intern Med 2001;135:32-40.

31. Breitbart W, Rosenfeld B, Roth A, et al. . The memorial delirium assessment scale. J Pain Symptom Manage 1997;13:128-37.

32. Heyn PC, Johnson KE, Kramer AF. Endurance and strength training outcomes on cognitively impaired and cognitively intact older adults: a meta-analysis. J Nutr Health Aging 2008;12:401-9.

33. Belmin J. La malnutrition protéino-énergétique du senior : une situation fréquente après une hospitalisation. Rev de Gériatrie 2006;31:415-9.

34. Milne AC, Avenell A, Potter J. Meta-analysis: protein and energy supplementation in older people. Ann Intern Med 2006;144:37-48.

35. Wolff JL, Kasper JD. Informal caregiver characteristics and subsequent hospitalization outcomes among recipients of care. Aging Clin Exp Res 2004;16:30713.

36. Balardy L, Voisin T, Cantet C, Vellas B; REAL.FR Group Predictive factors of emergency hospitalisation in Alzheimer's patients: results of one-year follow-up in the REAL.FR Cohort J Nutr Health Aging 2005;9:112-6.

37. Matsumoto N, Ikeda M, Fukuhara R, Shinagawa S, Ishikawa T, Mori T, Toyota Y, Matsumoto T, Adachi H, Hirono N, Tanabe H Caregiver burden associated with behavioural and psychological symptoms of dementia in elderly people in the local community. Dement Geriatr Cogn Disord 2007;23 219-24.

38. Cummings JL, Mega M, Gray K, Rosenberg-Thompson S, Carusi DA, Gornbein J The Neuropsychiatric Inventory: Comprehensive assessment of psychopathology in dementia. Neurology 1994;44:2308-18.

39. Imbert F, Lang PO, Meyer $\mathrm{N}$ et al. Description des conditions de vie de la population âgée de 75 ans ou plus vivant à domicile en Alsace. Rev Epidemiol Sante Publique 2005;53:153-65.

40. Coudin G. Family caregiver's reluctance toward community services: a social psychology perspective. Psychol Neuropsychiatr Vieil 2004;2:285-96.

41. Keough ME, Field TS, Gurwitz JH. A model of community-based interdisciplinary team training in the care of the frail elderly. Acad Med 2002;77:936.

42. Benedict L, Robinson K, Holder C. Clinical nurse specialist practice within the Acute care for Elders interdisciplinary team model. Clin Nurse Spec 2006;20:248-51.

43. Hilleret H, Falconnet C, Le Saint L, Perrenoud JJ, Michel JP, Vogt-Ferrier N Prescribing psychotropic drugs to patients aged 80 and over. Rev Med Suisse 2008;4:2405-8, 10-1

44. Thompson P, Lang L, Annells M. A systematic review of the effectiveness of inhome community nurse led interventions for the mental health of older persons. J Clin Nurs 2008;17:1419-27.

45. Robinson A, Street A. Improving networks between acute care nurses and an aged care assessment team. J Clin Nurs 2004;13:486-96. 